\title{
Carbon deposition behaviour in metal-infiltrated gadolinia doped ceria electrodes for simulated biogas upgrading in solid oxide electrolysis cells
}

\author{
V. Duboviks, ${ }^{a \pm}$ M. Lomberg, ${ }^{a}$ R. C. Maher, ${ }^{b}$ L. F. Cohen, ${ }^{b}$ N. P. Brandon ${ }^{a}$ and G. J. Offer ${ }^{c}$ \\ ${ }^{a}$ Department of Earth Science and Engineering, Imperial College, London SW7 2BP, United Kingdom \\ ${ }^{\mathrm{b}}$ Department of Physics, Imperial College, London SW7 2BP, United Kingdom \\ ${ }^{c}$ Department of Mechanical Engineering, Imperial College, London SW7 2BP, United Kingdom \\ ${ }^{ \pm}$Corresponding author. E-mail address: dubovik.vladislav@ gmail.com; phone: +44 7851579996 ;
}

fax 02075947444

\section{Abstract}

One of the attractive applications for reversible Solid Oxide Cells (SOCs) is to convert $\mathrm{CO}_{2}$ into $\mathrm{CO}$ via high temperature electrolysis, which is particularly important for biogas upgrading. To improve biogas utility, the $\mathrm{CO}_{2}$ component can be converted into fuel via electrolysis. A significant issue for SOC operation on biogas is carbon-induced catalyst deactivation. Nickel is widely used in SOC electrodes for reasons of cost and performance, but it has a low tolerance to carbon deposition. Two different modes of carbon formation on Ni-based electrodes are proposed in the present work based on ex-situ Raman measurements which are in agreement with previous studies. While copper is known to be resistant towards carbon formation, two significant issues have prevented its application in SOC electrodes - namely its relatively low melting temperature, inhibiting high temperature sintering, and low catalytic activity for hydrogen oxidation. In this study, the electrodes were prepared through a low temperature metal infiltration technique. Since the metal infiltration technique avoids high sintering temperatures, $\mathrm{Cu}-\mathrm{Ce}{ }_{0.9} \mathrm{Gd}_{0.1} \mathrm{O}_{2-\delta}(\mathrm{Cu}-\mathrm{CGO})$ electrodes were fabricated and tested as an alternative to $\mathrm{Ni}-\mathrm{CGO}$ electrodes. We demonstrate that the performance of $\mathrm{Cu}-\mathrm{CGO}$ electrodes is equivalent to Ni-CGO electrodes, whilst carbon formation is fully suppressed when operated on biogas mixture .

Keywords: Solid Oxide Fuel Cells; Electrolysis; Raman spectroscopy; Carbon deposition; Metal infiltration technique; Biogas upgrade.

\section{Introduction}

The EU has committed to a $20 \%$ reduction in greenhouse gas (GHG) emissions compared to 1990 levels by 2020 . To reach this objective, the EU Council set a binding target for alternative energies of $20 \%$ and a target of $10 \%$ for substitution of fossil with 
biofuels at 2020.[1] One promising renewable fuel is biogas which has the potential to contribute considerably to greenhouse gas emission reduction if used as a biofuel.[2] Biogas production has been steadily growing since 2001.[3] Currently, there is an increasing demand for biogas as a vehicle fuel or for injection to the natural gas grid.[3]

Biogas can be sustainably produced by the anaerobic digestion of biodegradable materials such as cow manure, plant material and other green or animal waste.[3] Biogas from organic waste digesters usually contains from $60 \%$ to $70 \% \mathrm{CH}_{4}$, from $30 \%$ to $40 \% \mathrm{CO}_{2}$ and $1 \% \mathrm{~N}_{2}$.[4] However, the presence of $\mathrm{CO}_{2}$ in fuel mixtures burned in internal combustion engines (ICEs) reduces the power output, especially for lower compression ratios.[5,6] Biogas fuelled ICEs also suffer from high levels of hydrocarbon emissions as a result of incomplete fuel combustion.[6] To enable the efficient use of biogas in most applications the gas must be upgraded, i.e. carbon dioxide, which constitutes a large part of the raw biogas, must either be separated from methane or converted into useful fuel. Since both $\mathrm{CH}_{4}$ and $\mathrm{CO}_{2}$ are identified as the main GHGs, biogas upgrading can serve both to minimise GHG emissions and increase their utility. Catalytic reforming of $\mathrm{CH}_{4}$ with $\mathrm{CO}_{2}$ is a promising technology for utilization and upgrade of these GHGs.[7,8] The dry reforming reaction was first proposed by Fischer Tropsch in 1928 and results in a mixture of $\mathrm{H}_{2}$ and $\mathrm{CO}$, often referred as synthesis gas (syngas). It is a more energy efficient process compared to steam reforming of methane and has significant potential in energy conversion and storage applications. The resulting gas mixture also has a higher $\mathrm{CO} / \mathrm{H}_{2}$ ratio making it suitable for the synthesis of higher hydrocarbons.[7,9]

For efficient biogas upgrading it is desirable to couple the process with the engine exhaust or another source of high grade heat.[4,10] The output gas composition of the reactor will depend on its temperature. Dry reforming is an endothermic reaction and when the fuel mix contains $70 \% \mathrm{CH}_{4}$ and $30 \% \mathrm{CO}_{2}$, it will only reach full conversion above $900{ }^{\circ} \mathrm{C}$ (as calculated using the Gibbs energy minimization method with HSC Chemistry software.)[11] In many cases such high grade heat is not available and $\mathrm{CO}_{2}$ is still present at the outlet of the reactor. Electrolysis has been shown to be economically viable and technologically feasible way of converting the $\mathrm{CO}_{2}$ into useful fuel.[12-14]

A major problem inhibiting large scale commercial application of biogas upgrading with Solid Oxide Cell (SOC) technology is catalyst deactivation due to carbon deposition. $[7,15]$ Thermodynamic calculations have been carried out using the HSC Chemistry software to evaluate the risk of carbon formation depending on the gas composition on the electrode considered in this study. The points in Fig. 1 represent the gas compositions that are considered for testing, and the dashed red line separates the region where carbon formation is predicted thermodynamically. $12 \% \mathrm{CO}-14 \% \mathrm{CO}_{2}-16 \% \mathrm{CH}_{4}-58 \% \mathrm{H}_{2}$ gas composition is the thermodynamic equilibrium mixture in the gas phase at $600{ }^{\circ} \mathrm{C}$. Again, the calculations have been performed using the Gibbs energy minimization method and do not take into account the presence of a catalyst or kinetic effects. It has been reported previously that no carbon formation occurs when operating cells in fuel cell mode in biogas mixtures contrary to the predictions of thermodynamic calculations.[16] Equally, it has been shown in the previous work, that kinetics may also cause an adverse effect.[17] Under polarisation in electrolysis mode, oxygen species are carried away from the fuel electrode to the air electrode through the electrolyte thus increasing the risk of carbon formation on the fuel electrode. 
As shown in Fig. 1, a gas composition primary consisting of $\mathrm{CO}_{2}$ with only $5 \%$ of $\mathrm{CO}$ lies almost on the border between the two regimes, while still in the region where carbon formation is thermodynamically unfavourable. However, if the proportion of $\mathrm{CO}$ is even slightly increased, there is the potential for it to cause carbon formation. In this case, from the thermodynamic point of view, the main candidate for formation of surface carbon deposits is CO disproportionation. The presence of methane, on the other hand, introduces another potential mechanism of carbon formation - namely the dissociation of $\mathrm{CH}_{4}$ into $\mathrm{C}$ and $\mathrm{H}$.[18,19] As a results, for SOCs operating on biogas fuels two forms of morphologically different carbon deposits are possible - amorphous carbon causes less damage and is easier to remove from the catalyst compared to graphitic types of carbon. Tracer temperature programmed oxidation experiments (a catalytic test carried out under ${ }^{13} \mathrm{CH}_{4} /{ }^{12} \mathrm{CO}_{2}$ ) have indicated that amorphous forms of carbon in $\mathrm{Ni}_{3} \mathrm{C}$ originates mostly from the methane dissociation reaction.[20] More stable carbon that is likely to encapsulate $\mathrm{Ni}$ particles or form graphitic whiskers arises from CO disproportionation (Boudouard reaction). [20]

Therefore, it is clear that it is necessary to prevent carbon deposits forming on the electrodes in order to enable SOCs to be successfully applied to biogas upgrade. Carbon formation on Ni-based electrodes can result in metal dusting - permanently damaging the electrode, whilst carbon deposition on $\mathrm{Cu}$-based electrodes was reported to deactivate the cell by filling the pores without causing physical damage.[21,22] However, it should be noted that although not experimentally observed, filling the pores with carbon is likely to lead to cracking of the electrode eventually. At the same time, a major obstacle in developing Cu-based electrodes is the relatively low melting temperature of $\mathrm{CuO}-1200^{\circ} \mathrm{C}$.[23] This is well below typical YSZ and CGO sintering temperatures.

Wet infiltration techniques avoid the need for elevated processing temperatures and offer a means to independently control the triple phase boundary (TPB) density and pore size. This fabrication technique is well described in the literature.[24-26] Briefly, a porous ceramic matrix is prepared by tape casting or screen-printing, and sintered without a metallic phase. The metallic phase is then introduced in a separate step which does not require high-temperature processing. Generally, the ceramic matrix is impregnated with the aqueous solution of a metal nitrate (e.g. $\left.\mathrm{Ni}\left(\mathrm{NO}_{3}\right)_{2}\right)$ and heated to ca. $500{ }^{\circ} \mathrm{C}$ to decompose the nitrate. Such low fabrication temperatures allow for a wide range of catalyst admixtures, including $\mathrm{Cu}$, to be introduced to the matrix, while significantly lowering the metal content required to obtain a fully percolated metal network. [27] It was demonstrated that percolation occurs at only $9-14$ vol\% for impregnated electrodes, compared to ca. 30 vol\% required for conventional electrodes.[25,27,28] Additionally, modelling studies and Focused Ion Beam (FIB) tomography have shown that the TPB density in infiltrated electrodes can be increased by an order of magnitude compared to conventional electrodes. [29,30] Another approach to the fabrication of $\mathrm{Cu}$-based electrodes involves using refractory metal additives to promote sintering at lower temperatures. [31]

In order to limit or even prevent the carbon-induced electrode deactivation in practical applications, it is crucial to identify the type of carbon, its distribution across the electrode and the exact conditions that lead to its formation. Raman spectroscopy has emerged as an effective tool for characterisation of carbon-induced SOC fuel electrode degradation.[32-35] Both in-situ and exsitu Raman characterisation is employed in this work to examine carbon formation on an emulated biogas fuelled SOC electrodes. 
$\mathrm{CeO}_{2}$-based oxides used for the fuel electrode is SOCs demonstrated low activation overpotentials and improved stability in numerous studies.[36] Therefore, Ni-infiltrated CGO electrodes are considered in the first part of the study, while the applicability of Cu-infiltrated electrodes is investigated in the second part.

\section{Experimental}

CGO ink for the fuel electrode scaffold was prepared by mixing $\mathrm{Ce}_{0.9} \mathrm{Gd}_{0.1} \mathrm{O}_{2-\delta}$ powder (Fuel Cell Materials) with Ethylcelulose N7 grade binder (IMCD UK/Hercules), a Hypermer KD15 dispersant (CRODA) and terpineol (Sigma Aldrich). The powder particle size was $0.20 \mu \mathrm{m}$ and surface area $5.8 \mathrm{~m}^{2} \mathrm{~g}^{-1}$ as specified by the supplier. The total solid fraction of the resulting ink was $75 \mathrm{wt} \%$. The ink was screen-printed to ca. $150 \mu \mathrm{m}$ thick (possible range of $130-170 \mu \mathrm{m}$ is specified by the manufacturer), $20 \mathrm{~mm}$ diameter Hionic $^{\mathrm{TM}}$ substrates from Fuel Cell Materials.[37] The electrode diameter was estimated to be $11 \mathrm{~mm}$ and thickness ca. $15 \mu \mathrm{m}$ (after sintering). A CGO interlayer was screen printed on the other side of the electrolyte using the same ink to prevent possible $\mathrm{SrZrO}_{3}$ and $\mathrm{La}_{2} \mathrm{Zr}_{2} \mathrm{O}_{7}$ phase formation between the electrolyte and the air electrode.[38,39] After sintering at 1350 ${ }^{\circ} \mathrm{C}$ in air for 2 hours, a CGO- $\left(\mathrm{La}_{0.6} \mathrm{Sr}_{0.4}\right)\left(\mathrm{Co}_{0.2} \mathrm{Fe}_{0.8}\right) \mathrm{O}_{3-\delta}$ air electrode was screen printed on top of the interlayer and sintered at $900{ }^{\circ} \mathrm{C}$ for 2 hours.

A number of the prepared scaffolds were then infiltrated with $\mathrm{Ni}$ nanoparticles by introducing drops of $2 \mathrm{M} \mathrm{Ni}^{\mathrm{N}}(\mathrm{NO})_{2}$ ethanol solution to the CGO scaffold, which instantly soaked into the porous scaffold. The rest of the scaffolds were infiltrated with $2 \mathrm{M}$ $\mathrm{Cu}\left(\mathrm{NO}_{3}\right)_{2}$ ethanol solution following the same procedure. Decomposition of the solution was achieved by heat-treating the electrodes for 30 minutes at $500{ }^{\circ} \mathrm{C}$. To achieve Ni percolation, the infiltration procedure was repeated 10 times. The $3 \mathrm{D}$ microstructure of the resulting Ni-infiltrated electrodes was characterised using FIB-SEM (Focused Ion Beam - Scanning Electron Microscopy) and has been reported elsewhere.[30] The pore volume fraction was estimated to be $20.1 \%$ with an average pore size of $0.30 \mu \mathrm{m}$. The average characteristic dimension of the Ni particles was estimated as $0.35 \mu \mathrm{m}$, and the Ni volume fraction was found to be 19.8 vol\%. The electrochemical performance of the cells infiltrated with Ni have also been characterised extensively and detailed results of this study are presented elsewhere.[25]

Symmetrical cells with both $\mathrm{Ni}$ - and $\mathrm{Cu}$-infiltrated electrodes were prepared and characterised using the configuration shown schematically in Fig. 2. Parts of the rig are removed in order to show the gas distribution and the current collection configuration clearly. Silver paste was evenly spread across the electrodes to ensure a good contact with the current collector. The silver paste used for these experiments develops large pores upon heating and hence does not present a significant gas barrier. The light grey area on the electrode in Fig. 2 shows where the silver paste was applied. Springs were used on both sides of the cell to ensure a good contact between the electrode and the gold mesh used as a current collector. The cell was fully enclosed in the quartz tube and the gas flowed parallel to the electrodes as demonstrated. The quartz tube was heated up to the required temperature in a Heraeus $^{\mathrm{TM}}$ tube furnace. The full cells have been exposed to the conditions that may be expected during $\mathrm{CO}_{2}$ electrolysis and 
biogas upgrade using a different experimental rig described elswhere. [40] This rig has been used because it allows optical access to the fuel electrode during operation, which is required for in-situ Raman measurements.

All electrolysis experiments were conducted at $600{ }^{\circ} \mathrm{C}$ with active air circulation over the electrode. The cells were heated up to temperature in $\mathrm{N}_{2}$ and once a stable temperature had been achieved pure $\mathrm{H}_{2}$ was allowed to flow through the fuel compartment for 5 minutes before switching to the target gas mixture to ensure that the Ni was fully reduced. The cell was allowed to stabilize at Open Circuit Potential (OCP) for another 5 minutes under the target gas mixture after which the reference EIS measurement was taken. The EIS was taken with the AC amplitude set to $5 \mathrm{~mA}$ in the frequency range from $1 \mathrm{MHz}$ to $0.1 \mathrm{~Hz}$. After that, the cell was left for 5 hours either at $-100 \mathrm{~mA}$ (EC mode) or OCP. The rig was then turned off and allowed to cool down to room temperature flowing $\mathrm{N}_{2}$.

Ex-situ Raman analysis was performed by first snapping the samples after which the cross-sections were analysed using a Renishaw RM-2000 CCD spectrometer. Spectra were collected using a $514 \mathrm{~nm}$ laser with a power of approximately $2.5 \mathrm{~mW}$ at the focal point. Light was focussed on to and collected from the sample surface using a $\times 50$ short working distance objective resulting in a beam diameter of approximately $1 \mu \mathrm{m}$. The microstructural changes were characterised using a LEO Gemini 1525 FEG-SEM microscope. SEM-EDX analysis was performed with JSM 6010 LA microscope fitted with Oxford instruments INCA energy dispersive X-ray spectrometer.

\section{Results and discussion}

\subsection{Current-induced degradation}

The Ni-infiltrated cells have been tested at open circuit potential (OCP) and under electrolysis conditions in order to study the effect of variable current supply to the cells. Before investigating the cell behaviour under biogas operation, a gas composition for which carbon deposition is not thermodynamically favourable was specifically chosen. This way the limitations of the thermodynamic predictions could also be checked. During the operation of a typical commercial $\mathrm{CO}_{2}$ electrolyser, the gas composition is likely to change from pure $\mathrm{CO}_{2}$ at the inlet to a mixture of $\mathrm{CO}-\mathrm{CO}_{2}$, the exact composition of which will depend on the specific location within the gas flow channel. Usually a significant portion of the gas stream at the outlet will be CO, with the exact proportion depending on the utilization and efficiency of the electrolyser. A gas composition that would be expected to correspond to the conditions close to the inlet of a commercial system $\left(95 \% \mathrm{CO}_{2}-5 \% \mathrm{CO}\right)$ was chosen for the initial experiments. As shown in Fig. 1, a $95 \% \mathrm{CO}_{2}-5 \% \mathrm{CO}$ gas mixture is below the carbon deposition line indicating that carbon deposition is not thermodynamically favourable under these conditions. The electrode was exposed to this gas composition for 5 hours while the cell was kept at OCP. No carbon formation was observed across the electrode cross-section according to ex-situ Raman analysis as demonstrated in Fig. 3a. Each spectrum represents the average of three different spectra collected at the same depth but at different locations along the electrode cross-section. A high concentration of $\mathrm{CO}_{2}$ shifts the equilibrium of the Boudouard reaction away 
from carbon formation and therefore no deposits are observed. This confirms the theoretical predictions performed with the HSC software.

In order to investigate the effect of the current, an identical electrode was exposed to the same gas composition $\left(95 \% \mathrm{CO}_{2}-\right.$ $5 \% \mathrm{CO}$ ) at $600{ }^{\circ} \mathrm{C}$ for 5 hours at $-100 \mathrm{~mA}$ (electrolysis mode). Fig. $3 \mathrm{~b}$ shows the average Raman response from the cross-section of this cell as a function of depth. A clear carbon signature, demonstrated by the presence of the characteristic D and G carbon peaks, is observed.[41] These spectra show that when the electrode is polarised, carbon formation occurs in a region extending as far as 8-10 $\mu \mathrm{m}$ away from the electrode/electrolyte interface. However, no carbon is formed on the surface of the electrode exposed to the gas flow. It has been suggested that the charge-transfer reactions in $\mathrm{CO}_{2}$ electrolysis mode can promote carbon deposition in conventional Ni-CGO cermet electrodes.[17] Utilizing the gas composition predicted theoretically and found experimentally not to cause carbon deposits at OCP on Ni-CGO electrodes, we demonstrate the effect of electrolysis current on carbon deposition in Ni infiltrated electrodes unambiguously. Assuming an electrolysis efficiency of $100 \%$ (it is lower in reality) at $-100 \mathrm{~mA}$ current, the $\mathrm{CO}_{2}$ consumption (and therefore $\mathrm{CO}$ production) is $0.8 \mathrm{ml} \mathrm{min}^{-1}$. According to the thermodynamic calculations, even that slight change in $\mathrm{CO}-\mathrm{CO}_{2}$ balance is sufficient to shift the thermodynamic equilibrium into the carbon deposition region of Fig. 1. Should carbon deposition have occurred because of the global change in gas composition, it would have been deposited across the whole cross-section of the electrode. The fact that the carbon peaks are not visible close to the surface suggests that there are significant changes in gas composition localised next to the most active part of the electrode. This effect has been discussed elsewhere[17], briefly - in the region close to the electrode/electrolyte interface $\mathrm{CO}_{2}$ conversion to $\mathrm{CO}$ is more facile creating the thermodynamic driving force for carbon formation.

Carbon deposits from the Boudouard reaction are expected to be graphitic.[20] However, the D peak is forbidden in perfect graphite following the fundamental selection rule $\mathbf{q}=\mathbf{0}$ ( $\mathbf{q}$ is the wave vector of the scattered phonon) and is only activated by the double resonance process that involves defect-phonon scattering.[42-44] Edges of the graphene sheets, the presence of atoms other than $\mathrm{C}$ in the lattice or the presence of $\mathrm{C}$ pentagons can all be considered as defects. As the D peak is rather prominent in the spectra in Fig. 3b, it is concluded that, firstly, sixfold aromatic rings, that give rise to D peak, are present; and also finite size graphitic clusters with defects are formed.

The ratio of $\mathrm{D}$ and $\mathrm{G}$ peak intensities is inversely related to the size of these clusters:

$$
\frac{I(D)}{I(G)}=\frac{C(\lambda)}{L_{a}}
$$

where $C$ is a wavelength dependent constant that at $514 \mathrm{~nm} \approx 44 \AA$. [42] As the ratio derived from the data in Fig. $3 \mathrm{~b}$ is $\approx 0.8$, the average cluster characteristic size should be $\approx 55 \AA$ Á. However, it should be noted that the broadening of the G peak is partially due to the D' peak at $1620 \mathrm{~cm}^{-1}$, which appears as the shoulder of $\mathrm{G}$ peak. The absence of a prominent second order CGO peak from the spectra suggests that the material is in a highly reduced state. One explanation for that is that the oxygen contained in the CGO lattice had been used to oxidise part of the adsorbed carbon atoms. 


\subsection{The effect of fuel-composition}

The presence of hydrogen atoms is known to have an effect on the morphology of carbon depositions. For example, DFT calculations have shown that $\mathrm{H}_{2}$ assists the dissociation of $\mathrm{CO}(\mathrm{ad})$ to $\mathrm{C}(\mathrm{ad})$ and $\mathrm{OH}(\mathrm{ad})$. [45] $\mathrm{Hydrogen}$ is produced in the $\mathrm{CH}_{4}$ dissociation reaction and therefore will play an important role in experiments with biogas. A $70 \% \mathrm{CH}_{4}-30 \% \mathrm{CO}_{2}$ gas composition will clearly favour carbon deposition in line with thermodynamic predictions (Fig. 1). However, results of in-situ Raman measurements in a $70 \% \mathrm{CH}_{4}-30 \% \mathrm{CO}_{2}$ gas composition at $600{ }^{\circ} \mathrm{C}$ did not reveal any surface deposits as shown in Fig. $4 \mathrm{a}$. Note that the negative values are caused by the uneven spectra baseline, affecting the integration. Limitations of the in-situ Raman technique, particularly the fact that it can only probe the surface of the electrode, and not the bulk, have been discussed elsewhere.[17] Thus, cross-sectional ex-situ Raman analysis has been carried out in order to confirm or disprove the absence of carbon deposits in the electrode.

Averaged spectra from several measurements shown in Fig. 4b demonstrate carbon formation occurs close to the surface of the electrode, but the peaks become extremely dispersed and almost disappear as the electrode/electrolyte interface is approached. The fact that there are no carbon D and G peaks in the bulk of the electrode suggests that the composition at the electrode/electrolyte interface is different from the composition at the gas/electrode interface. Part of the inlet gas will be converted into $\mathrm{H}_{2}$ and $\mathrm{CO}_{\text {in }}$ the SOC fuel compartment through the dry reforming reaction. The equilibrium gas composition at $600{ }^{\circ} \mathrm{C}$ is $12 \% \mathrm{CO}^{-14 \%} \mathrm{CO}$ $-16 \% \mathrm{CH}_{4}-58 \% \mathrm{H}_{2}$ as calculated using the HSC Chemistry software package. It is, however shown in Fig. 1 that this gas composition is still in the carbon deposition region and carbon deposits may therefore be expected.

Changes in gas-phase composition in conventional Ni-YSZ electrode SOCs fuelled with methane fuel streams have been discussed by Barnett et al.[46] They have shown that the use of a barrier layer with porosity $\phi=0.175$ impedes the rapid flow of methane into the bulk of the electrode and in certain cases can prevent carbon formation. Although there are no dedicated barrier layers on top of our electrodes, the porosity of the electrodes themselves is comparable $-\phi=0.20$.[30] That goes some way towards explaining the accumulation of carbon close to the surface when the cell is kept at OCP.

In addition to an overall decrease in the intensity, the lower three spectra in Fig. 4b demonstrate a highly dispersed peak at $\approx 1500 \mathrm{~cm}^{-1}$. The broad peak seems to be present on the upper two spectra as well, but is masked with carbon D and G peaks. The nature of this peak remains unclear, but it may be attributed to a highly amorphous ty pe of carbon. Extremely high defect concentrations can cause a decrease in the average bond angle and change the carbon atom connectivity. That is reflected in a reduction of intensity of the D peak and D' peaks and downward shift in frequency of the G peak to $\sim 1510 \mathrm{~cm}^{-1}$.[47] Equally, luminescence caused by electronic transitions of lanthanide ions have been reported to give rise to an ensemble of broad peaks between $1000 \mathrm{~cm}^{-1}$ and $1700 \mathrm{~cm}^{-1}$ in Raman spectra.[48] These ions are sometimes present as impurities at the bpm level in cerium-based reagents.[48] 
The broad peak centred at $1180 \mathrm{~cm}^{-1}$ is assigned to the second order CGO peak. Intensity of this peak increases in the lower few spectra in Figure 4b. Increase in intensity and the broadening of the peak in the lower spectra indicate that CGO becomes more oxidised close to the electrode/electrolyte interface when the electrode is exposed to $70 \% \mathrm{CH}_{4}-30 \% \mathrm{CO}_{2}$ at $\mathrm{OCP}$. The increase in CGO peak intensity is expected when there is a decrease in density of oxygen vacancies within the material.[49] Selective reduction of CGO across the electrode, that can explain the variation in second order CGO peak intensity in Fig. 4b, may have been caused by gradients in gas distribution. However, further experiments are required to either confirm or disprove it.

When the cell is polarised to $-100 \mathrm{~mA}$ (electrolysis mode) in biogas $\left(30 \% \mathrm{CO}_{2}-70 \% \mathrm{CH}_{4}\right)$, carbon is deposited across the whole depth of the electrode. This is demonstrated in Fig. 4c. However, the morphology of the deposition is different as indicated by changes in G peak intensity and dispersion. As discussed, the ratio of the D peak and G peak intensities indicates the amorphisation level or defect density of the graphite. The D/G ratio of $0.4-0.8$ is characteristic of highly structured carbon, such as CNT[50,51], while the ratio above 1 corresponds to a less structured carbon.[32] The carbon formed on the electrode exposed to $\mathrm{CH}_{4}-30 \% \mathrm{CO}_{2}$ at $-100 \mathrm{~mA}$ (Fig $4 \mathrm{c}$ ) is more graphitic than the carbon that formed on the electrode held at OCP (Fig 4b). This is inferred from the ratio of 0.76 (Fig $4 \mathrm{c}$ ) compared to 0.82 (Fig $4 \mathrm{~b}$ ) at $-1 \mu \mathrm{m}$; furthermore, at $-4 \mu \mathrm{m}$ the corresponding ratios are 0.69 (Fig 4c) and 0.76 (Fig 4b). The Raman peaks from the electrode exposed to $\mathrm{CH}_{4}-$ $30 \% \mathrm{CO}_{2}$ at $-100 \mathrm{~mA}$ (Fig 4c) are generally sharper than those measured on the OCP electrode (Fig 4b) and the D' peak is more intense. Both of these facts support the conclusion that the carbon is more graphitic on the electrode that was tested at $-100 \mathrm{~mA}$. It is also observed that the carbon becomes more graphitic as a function of depth into the electrode. This is seen most clearly by comparing the ratio at $-1 \mu \mathrm{m}$ and that at $-13 \mu \mathrm{m}$ on the electrode held at $-100 \mathrm{~mA}$ which are 0.76 and 0.61 respectively.

Taking into account the results shown in Fig. $3 \mathrm{~b}$ and 4c, it is likely that two different processes are responsible for the carbon formation in the electrode polarised to $-100 \mathrm{~mA}$ in biogas. This is in contrast to a single mechanism involved in carbon formation under the $\mathrm{CO}_{-} \mathrm{CO}_{2}$ mixture and -100mA (Fig. 3b). Significantly more amorphous carbon is known to be the results of $\mathrm{CH}_{4}$ disassociation - part of the dry reforming that is likely to occur close to the surface of the electrode. $\mathrm{CO}_{2}$ disassociation, on the other hand, can result from the electrode polarisation and is known to incur graphitic carbon deposits.[20] That explains the differences seen in the spectra in Fig 4b. While the peak intensities varied across the electrode, the trend of carbon formation was always the same, as depicted in Fig. $4 \mathrm{~b}$. The effects of the current collector configuration on the carbon formation when the cell is operated with methane has been reported previously.[52] It is important to note that the non-porous region of the current collection may affect the partial pressures of the gases on the electrode and hence the tendency for carbon formation in these places.

\subsection{Change of the microstructure}

Good microstructural stability of the electrode is essential for the advancement of the infiltration technique. De-wetting between the Ni and CGO phases and particle coarsening have been previously discussed by Lomberg et al.[25] Addition of low surface energy oxides, such as $\mathrm{MgO}$, has been suggested to prevent these issues.[53] It has been reported that the agglomeration of Ni particles has been observed after 4 
days of cell exposure to operational conditions.[25] The current study is limited to 5 hour experiments and as such only considers short term structural degradation.

Formation of filamentous carbon has been observed to occur within Ni/YSZ electrodes after 5 hrs exposure to methane at 600 ${ }^{\circ} \mathrm{C}$.[54] Carbon filament formation has also been recently observed after co-electrolysis of $\mathrm{H}_{2} \mathrm{O}$ and $\mathrm{CO}_{2}$ in Ni/YSZ supported SOCs at high current densities.[55] Formation of carbon whiskers has been proposed as an initial mechanism for carbon dissolution into the Ni that leads to irreversible degradation of the electrode structure.[56] The solubility of carbon in $\mathrm{Ni}$ is high, about $0.9 \%$ at $900{ }^{\circ} \mathrm{C}$, i.e. for each 1000 atoms of $\mathrm{Ni}$ there are 9 atoms of $\mathrm{C}$ in the structure.[57] The nucleation of filamentous carbon is caused by the formation of a supersaturated carbon solution within the Ni. However, doping Ni/YSZ electrodes with ceria was shown to change the morphology of carbon towards amorphous surface-located structures, which are less detrimental to the electrode.[58] It is, therefore, important to distinguish between the carbon deposited on the surface on $\mathrm{Ni}$ and the carbon dissolving into the Ni particles. Surface carbon may be easier to remove electrochemically, unless it forms highly graphitic structures, whilst dissolution of carbon into the Ni causes irreversible damage to the electrode, e.g. metal dusting.[59]

Raman analysis in the current study has shown that the carbon formed on Ni infiltrated electrode is amorphous, but there is no indication of whether it dissolves into the $\mathrm{Ni}$ or remains on the surface of the catalyst. SEM analysis provides further insights into the mechanism of carbon formation and indicates the formation of whisker-type structures as shown in Fig. 5c and 5d. Since carbon is a light element, it may prove difficult to separate the carbon that formed during the experiment from the contaminative carbon using EDX analysis.[60] However, the correlation between the Raman data and the microscopy analysis allows assigning the filamentous structures in Fig. 5c and 5d to carbon deposits with reasonable confidence. It has been previously proposed that carbon can diffuse through the metal particle and precipitate at the backside until the particle is lifted up from the substrate and the filament is formed.[61] Filament thickness varies with temperature - long 30 $-40 \mathrm{~nm}$ thick carbon filaments have been observed at $500{ }^{\circ} \mathrm{C}$ on Ni/YSZ electrodes exposed to dry methane.[62] It was also reported that at higher temperatures, filaments of $60-110 \mathrm{~nm}$ thickness are usually formed under the same conditions.[62] Since the whisker size is related to the Ni particle size, which catalyse the formation of these structures, thicker filaments may be indicative of Ni particle agglomeration. These thicker filaments were shown to encapsulate smaller nickel particles.[62]

An electrocatalytic mechanism catalysed by YSZ particles has also been proposed for carbon nanotube (CNT) growth in Ni-YSZ electrodes during $\mathrm{CO}_{2}$ and $\mathrm{H}_{2} \mathrm{O}$ electrolysis. [63] It is suggested that $\mathrm{CO}$ adsorption on the YSZ surface is followed by its disassociation into an oxide ion, which occupies the oxygen vacancy within zirconia, and a surface carbon atom. Mixed ionic conductivity on the ceramic phase is essential for this mechanism to function. Mogensen et al. suggest that zirconia exhibits mixed ionic and electronic conductivity under strong polarisation.[63] A similar mechanism may be at work in our electrodes, since CGO is well known for its mixed conductivity under reducing conditions.[64]

SEM micrographs before and after Ni impregnation are shown in Fig. 5a and 5b respectively. The CGO scaffold appears to be covered with an uninterrupted layer of Ni after 10 infiltrations. At the same time it is still possible to distinguish individual Ni particles in Fig. $5 \mathrm{~b}$, roughly $100 \mathrm{~nm}$ in diameter. According to the SEM analysis presented in Fig. 5, ca. 100nm thick carbon filaments are formed after 5 hour 
exposure to $95 \% \mathrm{CO}_{2}-5 \% \mathrm{CO}$ under $-100 \mathrm{~mA}$ bias. Although carbon nanotube formation in Ni-YSZ electrodes has been reported in several studies, no comments have been made regarding the nanotube geometrical structure.[54,58] Based on Raman and SEM analysis, it is concluded that amorphous carbon nanotubes (a-CNTs) are formed in the electrodes.[50] These are multi-walled structures, since the dimensions of the filamentous structures (Fig. 5c) are significantly larger than would be expected for a single-walled nanotube. In addition, an ideal single-walled nanotube (SWNT) with perfect concentric graphene shells would demonstrate G peak splitting into G+ and Gassigned to circumferential and axial modes.[65] The Raman analysis did not provide any indication of this in the current study. There is no clear difference between the amorphous multi-walled carbon nanotube and a carbon filament. Since the use of the term nanotube without providing additional information regarding the geometrical properties of the structure can be misleading, it is suggested that these structures should be referred to as filaments. While it is likely that some carbon dissolves into the Ni of the electrodes, it will also encapsulate smaller particles which then remain inside the filaments as has been demonstrated in other studies.[62,63] The thickness of the carbon filaments is similar to the characteristic dimensions of the Ni particles in our electrodes, suggesting that carbon might be precipitating at the rear of the particle to form a graphite whisker as was hypothesised in previous studies.[66] The results also indicate that filaments are formed both with and without the presence of $\mathrm{CH}_{4}$, contrary to the conclusion of Alstrup et al. that filaments are only formed when $\mathrm{CH}_{4}$ is present.[67] Alstrup et al. have employed $\mathrm{Ni} / \mathrm{SiO}_{2}$ electrodes and have not considered bias effects in their studies. This emphasises the effect of polarisation and the choice of the ceramic phase of the electrode on the mechanism of carbon formation. However, the filaments formed in $30 \% \mathrm{CO}_{2}-70 \%$ $\mathrm{CH}_{4}$ tend to be longer as can be seen in Fig. 5d, and are therefore more likely to cause mechanical damage to the electrode.

Another significant issue resulting from carbon formation is the cracks that develop within the cell which can result in its abrupt failure.[52] Delamination of the electrode due to carbon deposits promoted by cell polarisation in (co-) electrolysis conditions has been reported previously.[17,55] Structural differences on the interface between the electrode and the electrolyte are examined in Fig. 6 . Chosen SEM micrographs are characteristic of the whole interface of the corresponding electrode. Whisker-like structures, identified as carbon filaments are seen on the interface only in those samples that have been polarized during the experiment. That is consistent with the Raman analysis of the electrode cross-sections. Delamination occurred only when the electrode was polarised while exposed to the gas mixture containing methane. This gas composition thermodynamically favours carbon deposition (Fig. 1), unlike the $\mathrm{CO}-\mathrm{CO}_{2}$ mixture used in the previous experiments. Samples polarised in methane have also demonstrated a much stronger carbon Raman signature (Fig. 4). It is likely that the increased rate of carbon formation causes Ni dusting, occurring via direct growth of graphite into the metal and local expansion of the electrode structure close to the electrolyte. This expansion in combination with the formation of longer carbon filaments results in fracture of the cell observed in Fig. 6d.

\subsection{Towards robust Solid Oxide Electrolysis Cell (SOEC) electrodes}

Operation under conditions that thermodynamically favour carbon deposition will only be possible if the electrode is specifically designed to be resistant to carbon formation. At the same time as being by far the most widely used catalyst in SOC technology, Ni is also a good catalyst for C-C bond formation. Numerous studies report Solid Oxide Fuel Cell (SOFC) degradation and failure due to carbon 
formation on the electrode.[21,33,54,56,58,68-71] Recent studies, including this, have also shown that the same problem persists under electrolysis conditions.[17,55,63,72] It has been hypothesised that doped ceria can provide sufficient electrocatalytic activity alone such that the metal component is only required for efficient current collection.[73] In that case, the choice of metal should be dictated by its conductivity, rather than its catalytic activity. That makes $\mathrm{Cu}$ an ideal candidate, as it is excellent conductor and poor $\mathrm{C}-\mathrm{C}$ and $\mathrm{C}-\mathrm{H}$ bond activation catalyst.[24,74] The solubility of $\mathrm{C}$ in $\mathrm{Cu}$ is also much lower than that in Ni.[57]

Conventional cermet electrode manufacturing techniques do not allow the use of pure Cu because of its low melting temperature.[24,75] The infiltration technique avoids high sintering temperatures and provide the opportunity to develop carbon-tolerant $\mathrm{Cu}-\mathrm{CGO}$ electrodes. The investigation of $\mathrm{Cu}-\mathrm{CGO}$ electrodes in this study aims to compare their electrochemical performance and carbon tolerance with equivalent Ni-CGO electrodes.

$\mathrm{Ni}-\mathrm{CGO}$ and $\mathrm{Cu}-\mathrm{CGO}$ electrodes performance have been tested in the symmetrical cell configuration shown in Fig. 2 . The cells were tested at $600{ }^{\circ} \mathrm{C}$ in the gas stream of $50 \% \mathrm{H}_{2}$ and $50 \% \mathrm{~N}_{2}$, humidified at room temperature. Results of the measurements over the frequency range of $100 \mathrm{kHz}$ to $0.1 \mathrm{~Hz}$ are shown in Fig. $7 \mathrm{~b}$ and $7 \mathrm{c}$. The, negative imaginary resistance at high frequencies corresponds to the inductive component, most likely originating from the leads in the test rig. The ohmic resistance $\left(R_{O h m}\right)$, extracted from the intercept of the spectra with the real axis is attributed to the response of the electrolyte, current collectors and the resistance of the leads. The values of $R_{O h m}$, estimated from the insets in Figure $7 \mathrm{~b}$ and Fig. $7 \mathrm{c}$, are $7.5 \Omega$ and $6.6 \Omega$ for $\mathrm{Cu}-\mathrm{CGO}$ and Ni-CGO symmetrical cells respectively. Since $\mathrm{Cu}$ has a better electronic conductivity, the $\mathrm{Cu}-\mathrm{CGO}$ electrode could be expected to have a lower $R_{\text {Ohm }}$. However, this is not the case, on the contrary, $\mathrm{Cu}$ CGO electrode has $\sim 1 \Omega$ larger $R_{O h m}$. The difference in the ohmic resistance is likely due to the following reasons. Firstly, since the measurements were performed in a 2-point configuration, slight variations in contact resistance between the current collectors and the electrodes as well as between the potentiostat connectors and the current collector leads could have contributed to the difference in high frequency intercept in Fig. $7 \mathrm{~b}$ and Fig. 7c. Secondly, possible variation in electrolyte thickness $-130-170 \mu \mathrm{m}$, as specified by the manufacturer[37], could have led to the difference in ohmic resistance as observed in Fig. 7b and Fig. 7c.

A typical EIS response of a symmetrical cell consists of three features at low (ca. $6 \mathrm{~Hz}$ ), intermediate (ca. $1 \mathrm{kHz}$ ) and high (up to $20 \mathrm{kHz}$ ) frequencies as identified by a rigorous modelling approach by Bessler et al. employing conventional Ni-YSZ symmetrical cells.[76] Both the low and the intermediate frequency responses are associated with the diffusion processes, and the high frequency process is due to the charge-transfer reaction.[76] Assignment of the physiochemical processes in this work is based on these findings. The complex non-liner least-squares (CNLS) fit of the impedance data in Fig. 7b and 7c was carried out with the commercial program ZView using the equivalent circuit shown in Fig 7a. The high frequency process (ca. $5 \mathrm{kHz}$ ) is assigned to charge-transfer resistance at the electrodes. Equivalent resistance for this process is ca. $0.4 \Omega$. The geometric area of each electrode is ca. $1 \mathrm{~cm}^{2}$, therefore the corresponding Area Specific Resistance (ASR) is $0.2 \Omega \cdot \mathrm{cm}^{2}$. This is in good agreement with the value reported for Ni-CGO electrodes elsewhere.[25] The large semicircle at low frequencies in Fig. $7 \mathrm{~b}$ and $7 \mathrm{c}$ is likely to overlap with the intermediate frequency feature and corresponds to the gas diffusion processes and possibly the redox behaviour of the CGO scaffold. The fact that the response at the very low frequencies approaches that of a resistor indicates that the characteristic size of the pore is smaller than the free path length of the diffusing particles. The low 
frequency semicircle is slightly larger in the $\mathrm{Cu}-\mathrm{CGO}$ electrode, which most likely reflects the reduction in porosity of the sample compared to the Ni-CGO electrode. SEM-EDS analysis of the Ni-CGO and Cu-CGO electrode cross-sections suggests that $\mathrm{Cu}$ has a higher tendency to agglomerate, forming a relatively dense layer on the surface of the electrode as shown in Fig. 7d. It has been previously reported that the increase in $\mathrm{Cu}$ content in $\mathrm{Ni}_{\mathrm{x}} \mathrm{Co}_{1-\mathrm{x}}-\mathrm{Ce}_{0.8} \mathrm{Sm}_{0.2} \mathrm{O}_{1.9}$ electrodes leads to decrease in electrode porosity.[77] This might explain the agglomeration of $\mathrm{Cu}$ at the surface of electrode as shown in Fig. 7d. This is likely to reduce gas diffusion in the electrode. Ni, on the other hand, is evenly spread across the whole electrode according to Fig. 7e which may explain the higher diffusion resistance of the Cu-CGO electrode. However, the metal phase is distributed across the entire electrode in both cases, which is in line with FIB-SEM results for the Ni infiltrated CGO electrode reported elsewhere.[30]

Several processes in Fig. 7b and Fig. 7c are likely to overlap and partially mask each other. In principle, deconvolution of the spectra can be achieved by method of distributions of relaxation times. Ivers-Tiffee et al. have pioneered this approach for EIS result interpretation. [78] The method relies on Fourier analysis of the impedance spectra, in combination with extrapolation techniques and digital filtering in the transformed space. It can provide direct access to the kinetic parameters of underlying processes, however incorrect choice of the regularisation parameter for filtering the measured data may lead to false peaks and oscillations.[79] Extremely high stability of the measurement is also required for the correct deconvolution. Because of the emphasis of this work on carbon deposition analysis, interpretation of the impedance data is limited to semi-imperial approach of equivalent circuits.

Based on the EIS results in Fig. 7 there are no significant differences in the performance between CGO scaffolds infiltrated with either $\mathrm{Cu}$ or $\mathrm{Ni}$. This confirms the observation of Haile et al[80], suggesting that metal component in CGO-based electrodes serves mainly as a current collector. Ex-situ Raman characterisation of the cross-section of the Cu-CGO electrode performed after a 5 hour exposure to $70 \%$ $\mathrm{CH}_{4}-30 \% \mathrm{CO}_{2}$ at $-100 \mathrm{~mA}$ indicated no carbon formation, as shown in Fig. 8. Each spectrum shown in Fig. 8 is the average of several spectra collected across the electrode following exactly the same procedure described earlier for the Ni-CGO electrode analysis. Spectra in Figure 8 are entirely free of carbon features. This is in line with the previous observations of stable operation achieved for the composite copper and ceria cermets under direct methane fuel cell operation (thermodynamically favourable for carbon formation).[81] Carbon deposits have been reported to form in considerably lower amounts in the copper and ceria systems tested in methane compared to the extensive carbon deposits formed during equivalent tests in the presence of nickel.[82] Results presented in this study demonstrate the absence of carbon deposits in $\mathrm{Cu}-\mathrm{CGO}$ electrodes operated in electrolysis mode under simulated biogas. Ex situ Raman analysis of the snapped electrodes' cross sections was performed in order to overcome the inherent near-surface limitation of the Raman technique. The electrochemical performance of $\mathrm{Cu}-\mathrm{CGO}$ electrodes was found to be on the same level as the performance of Ni-CGO electrodes, thus making $\mathrm{Cu}-\mathrm{CGO}$ electrodes an excellent candidate for biogas upgrade in SOCs.

The performance of the electrodes discussed in this study has only been tested under $\mathrm{H}_{2}$. Although $\mathrm{H}_{2} / \mathrm{H}_{2} \mathrm{O}$ kinetics may not have a significant dependence on the nature of the metal component of the electrode, an early study on all-ceramic electrodes conducted by Gorte et al has shown that when $\mathrm{CH}_{4}$ takes part in the electrochemical reactions on the electrode, small amounts of highly catalytic metal, such as Rh, increase the performance of the cell.[83] The metal phase was highly dispersed in the experiments performed by Gorte et al., and presumably 
did not affect the current-carrying properties of the electrodes, acting only as a catalyst. Although addition of Pt-group metals to Cu-CGO electrodes may be challenging due to strong tendency for alloy formation, precious metals can enhance kinetics of reactions involving hydrocarbons.[24,83] This, in combination with subsequent advances in the infiltration technique for SOC electrode manufacturing, is a prospective direction for future research. Although fabrication of the infiltrated electrodes is time consuming and not yet optimized for mass manufacturing, novel additive manufacturing techniques may help to overcome this issue. Additive manufacturing techniques, such as selective laser sintering, have already been shown to be applicable to the fabrication of certain fuel cell components[84,85] and successfully applied to porous cermet electrode manufacture for other applications.[86] Provided that this technique can generate materials of the required porosity, it can potentially be applied for cost effective manufacturing of $\mathrm{Cu}-\mathrm{CGO}$ electrodes.

\section{Conclusions}

The viability of biogas upgrade using SOC technology has been demonstrated. It has been shown that, while the Ni-based electrodes only develop carbon deposits close to the electrode/electrolyte interface when exposed to $\mathrm{CO}_{2} / \mathrm{CO}$ gas mixtures, the addition of $\mathrm{CH}_{4}$ triggers carbon formation across the whole electrode volume. Identification of two different mechanisms of carbon formation in the Ni-CGO electrodes was possible through the combination of thermodynamic modelling coupled with Raman spectroscopy cross-sectional analysis. Formation of a relatively graphitic carbon in the most electrochemically active part of the electrode was attributed to an electrocatalytic process. Thermodynamic predictions are in line with the observation of a less graphitic carbon, formed closer to the gas/electrode interface in the presence of methane. This confirms the observations by Swaan et al., attributing the less stable form of carbon formed on $\mathrm{Ni}_{1}$ in $\mathrm{CO}_{2} / \mathrm{CH}_{4}$ gas mixture to the effect of methane activation.[20] Encapsulating carbon as opposed to filament growth has been identified as the dominant mechanism on $\mathrm{Ni} / \mathrm{SiO}_{2}$ in pure $\mathrm{CO}$ at $550{ }^{\circ} \mathrm{C}$ by Alstrup et al. [67] While carbon encapsulation of small particles is not excluded in this work, filaments formation on Ni-CGO electrodes at similar temperatures is shown to be prominent even without $\mathrm{CH}_{4}$ in the gas mixture.

The low processing temperatures characteristic of the infiltration technique allowed for $\mathrm{Cu}$-based electrodes to be fabricated and tested in this work. Ceria impregnated $\mathrm{Cu}$ electrodes have previously been found to be poor electro-catalysts for $\mathrm{H}_{2}$ oxidation. [75] Although a successful fuel cell operation has been previously reported with $\mathrm{Cu}$-based electrodes in another study, the absence of carbon formation has not been experimentally confirmed in these electrodes.[81] Also, Cu-based electrodes have not been previously considered for the electrolysis of carbonaceous mixtures. The performance of $\mathrm{Cu}-\mathrm{CGO}$ electrodes towards hydrogen electro-oxidation was found to be on the same level as Ni-based electrodes in this study. This confirms the hypothesis proposed by Haile $e l$ al., that the metal-catalysed pathway does not contribute significantly to electrocatalysis.[80] This, however, should not be extended to the operation of hydrocarbons without further investigation. More importantly, $\mathrm{Cu}-\mathrm{CGO}$ electrodes were unequivocally demonstrated to suppress carbon deposits in aggressive biogas mixtures. High electrocatalytic activity in combination with carbon tolerance makes $\mathrm{Cu}$-CGO a desirable candidate for reversible SOCs.

\section{Acknowledgement}


The authors would like to thank the Engineering and Physical Sciences Research Council (U.K.) EPSRC(GB)) for funding, in particular the Supergen fuel cell programme and a Career Acceleration Fellowship for Gregory Offer EP/I00422X/1 and funding under EP/J003085/1 (RCM), as well as the Alan Howard Scholarship for PhD project funding. The authors would also like to acknowledge the valuable insights gained from the discussions with Dr Enrique Ruiz-Trejo and other colleagues in the Electrochemical Science \& Engineering group at Imperial College London.

\section{References}

[1] Communication from the Commision to the Council and the European Parliament, Brussels, 2007.

[2] A. Tilche, M. Galatola, Water Sci. Technol. 57 (2008) 1683.

[3] F. Bauer, C. Hulteberg, T. Persson, D. Tamm, Biogas Upgrading - Review of Commercial Technologies, 2013.

[4] C.S. Lau, a. Tsolakis, M.L. Wyszynski, Int. J. Hydrogen Energy 36 (2011) 397.

[5] S.O.B. Shrestha, G.A. Karim, Appl. Therm. Eng. 21 (2001) 331.

[6] S. Swami Nathan, J.M. Mallikarjuna, A. Ramesh, Energy Convers. Manag. 51 (2010) 1347.

[7] S. Wang, G.Q.M. Lu, G.J. Millar, Energy \& Fuels 0624 (1996) 896.

[8] S.E. Evans, J.Z. Staniforth, R.J. Darton, R.M. Ormerod, Green Chem. 16 (2014) 4587.

[9] E.C. Alyea, D. He, J. Wang, Appl. Catal. A Gen. 104 (1993) 77.

[10] C. Graves, S.D. Ebbesen, M. Mogensen, K.S. Lackner, Renew. Sustain. Energy Rev. 15 (2011) 1.

[11] W.B. White, S.M. Johnson, G.B. Dantzig, J. Chem. Phys. 28 (1958) 751.

[12] Q. Fu, C. Mabilat, M. Zahid, A. Brisse, L. Gautier, Energy Environ. Sci. 3 (2010) 1382.

[13] L. Chen, F. Chen, C. Xia, Energy Environ. Sci. Accepted m (2014).

[14] S.D. Ebbesen, J.B. Hansen, M. Mogensen, ECS Trans. 57 (2013) 3217.

[15] K. Girona, J. Laurencin, J. Fouletier, F. Lefebvre-Joud, J. Power Sources 210 (2012) 381.

[16] Y. Shiratori, T. Oshima, K. Sasaki, Int. J. Hydrogen Energy 33 (2008) 6316.

[17] V. Duboviks, R.C. Maher, M. Kishimoto, L.F. Cohen, N.P. Brandon, G.J. Offer, Phys. Chem. Chem. Phys. 16 (2014) 13063.

[18] M.A. Goula, A.A. Lemonidou, A.M. Efstathiou, J. Catal. 161 (1996) 626.

[19] Z. Wang, X.-M. Cao, J. Zhu, P. Hu, J. Catal. 311 (2014) 469.

[20] H.M. Swaan, V.C.H. Kroll, G.A. Martin, C. Mirodatos, Catal. Today 21 (1994) 571.

[21] C.M. Chun, J.D. Mumford, T.A. Ramanarayanan, J. Electrochem. Soc. 147 (2000) 3680. 
[22] T. Kim, G. Liu, M. Boaro, S.-I. Lee, J.M. Vohs, R.J. Gorte, O.H. Al-Madhi, B.O. Dabbousi, J. Power Sources 155 (2006) 231.

[23] H. V. Wartenberg, H.J. Reusch, E. Saran, Zeitschrift Fuer Anorg. Und Allg. Chemie 230 (1937) 257.

[24] R.J. Gorte, J.M. Vohs, J. Catal. 216 (2003) 477.

[25] M. Lomberg, E. Ruiz-Trejo, G. Offer, N.P. Brandon, J. Electrochem. Soc. 161 (2014) F899.

[26] S.P. Jiang, S. Zhang, Y.D. Zhen, a. P. Koh, Electrochem. Solid-State Lett. 7 (2004) A282.

[27] T. Klemens $\varnothing$, K. Thydén, M. Chen, H.-J. Wang, J. Power Sources 195 (2010) 7295.

[28] D.W. Dees, T.D. Claar, D.C. Fee, J. Electrochem. Soc. 134 (1987) 2141.

[29] W. Zhu, D. Ding, C. Xia, Electrochem. Solid-State Lett. 11 (2008) B83.

[30] M. Kishimoto, M. Lomberg, E. Ruiz-Trejo, N.P. Brandon, J. Power Sources 266 (2014) 291.

[31] T.A.G. Restivo, S.R.H. Mello-Castanho, J.A. Tenorio, J. Therm. Anal. Calorim. 118 (2014) 75.

[32] M.B. Pomfret, J.C. Owrutsky, R.A. Walker, J. Phys. Chem. B 110 (2006) 17305.

[33] M. Yoshinaga, H. Kishimoto, M.E. Brito, K. Yamaji, T. Horita, H. Yokokawa, J. Ceram. Soc. Japan 119 (2011) 307.

[34] K.S. Blinn, H. Abernathy, X. Li, M. Liu, L.A. Bottomley, M. Liu, Energy Environ. Sci. 5 (2012) 7913.

[35] R.C. Maher, V. Duboviks, G.J. Offer, M. Kishimoto, N.P. Brandon, L.F. Cohen, Fuel Cells 13 (2013) 455.

[36] C. Sun, H. Li, L. Chen, Energy Environ. Sci. 5 (2012) 8475.

[37] FuelCellMaterials, (2015).

[38] A. Mai, V. Haanappel, F. Tietz, D. Stover, Solid State Ionics 177 (2006) 2103.

[39] E.P. Murray, S.A. Barnett, Solid State Ionics 143 (2001) 265.

[40] E. Brightman, R. Maher, G.J. Offer, V. Duboviks, C. Heck, L.F. Cohen, N.P. Brandon, Rev. Sci. Instrum. 83 (2012) 053707.

[41] R.J. Nemanich, S.A. Solin, Phys. Rev. B 20 (1979) 392.

[42] F. Tuinstra, J.L. Koenig, J. Chem. Phys. 53 (1970) 1126.

[43] C. Thomsen, S. Reich, Phys. Rev. Lett. 85 (2000) 5214.

[44] A.C. Ferrari, Solid State Commun. 143 (2007) 47.

[45] S. Storsæter, D. Chen, A. Holmen, Surf. Sci. 600 (2006) 2051.

[46] H. Zhu, A.M. Colclasure, R.J. Kee, Y. Lin, S.A. Barnett, J. Power Sources 161 (2006) 413.

[47] A. Ferrari, J. Robertson, Phys. Rev. B 61 (2000) 14095.

[48] P. Fornasiero, A. Speghini, R. Di Monte, M. Bettinelli, A. Bigotto, V. Sergo, M. Graziani, S. Chimiche, Chem. Mater. (2004) 1938.

[49] R.C. Maher, L.F. Cohen, P. Lohsoontorn, D.J.L. Brett, N.P. Brandon, J. Phys. Chem. A 112 (2008) 1497. 
[50] Z.D. Hu, Y.F. Hu, Q. Chen, X.F. Duan, L.-M. Peng, J. Phys. Chem. B 110 (2006) 8263.

[51] S. Pacley, W.C. Mitchel, P.T. Murray, D. Anderson, H.E. Smith, E. Beck-Millerton, A.A. Voevodin, J. Electron. Mater. 42 (2012) 417.

[52] A. Singh, S. Islam, M.A. Buccheri, J.M. Hill, Fuel Cells 13 (2013) 703.

[53] B. Hua, W. Zhang, M. Li, X. Wang, B. Chi, J. Pu, J. Li, J. Power Sources 247 (2014) 170.

[54] H. He, J.M. Hill, Appl. Catal. A Gen. 317 (2007) 284.

[55] Y. Tao, S.D. Ebbesen, M.B. Mogensen, J. Electrochem. Soc. 161 (2014) F337.

[56] Y. Kim, J.H. Kim, J. Bae, C.W. Yoon, S.W. Nam, J. Phys. Chem. C 116 (2012) 13281.

[57] X. Li, W. Cai, L. Colombo, R.S. Ruoff, Nano Lett. 9 (2009) 4268.

[58] V. Alzate-Restrepo, J.M. Hill, J. Power Sources 195 (2010) 1344.

[59] D.J. Young, J. Zhang, C. Geers, M. Schütze, Mater. Corros. 62 (2011) 7.

[60] J. Qiao, N. Zhang, Z. Wang, Y. Mao, K. Sun, Y. Yuan, Fuel Cells 9 (2009) 729.

[61] J.-W. Snoeck, G.F. Froment, M. Fowles, J. Catal. 169 (1997) 240.

[62] B. Novosel, M. Marinšek, J. Maček, J. Fuel Cell Sci. Technol. 9 (2012) 061003.

[63] Y. Tao, S.D. Ebbesen, W. Zhang, M.B. Mogensen, ChemCatChem 6 (2014) 122.

[64] T. Setoguchi, K. Okamoto, K. Eguchi, H. Arai, J. Electrochem. Soc. 139 (1992) 2875.

[65] A.C. Ferrari, J.C. Meyer, V. Scardaci, C. Casiraghi, M. Lazzeri, F. Mauri, S. Piscanec, D. Jiang, K.S. Novoselov, S. Roth, a. K. Geim, Phys. Rev. Lett. 97 (2006) 187401.

[66] J.R. Rostrup-Nielsen, D.L. Trimm, J. Catal. 48 (1977) 155.

[67] I. Alstrup, M.T. Tavares, C.A. Bernardo, O. Soerensen, J.R. Rostrup-Nielsen, Mater. Corros. 49 (1998) 367.

[68] C.M. Finnerty, N.J. Coe, R.H. Cunningham, R.M. Ormerod, Catal. Today 46 (1998) 137.

[69] A. Singh, J.M. Hill, J. Power Sources 214 (2012) 185.

[70] J. Mermelstein, M. Millan, N.P. Brandon, J. Power Sources 196 (2011) 5027.

[71] M.B. Pomfret, J. Marda, G.S. Jackson, B.W. Eichhorn, A.M. Dean, R.A. Walker, Fuel Cell 112 (2008) 5232.

[72] V. Duboviks, R.C. Maher, G. Offer, L.F. Cohen, N.P. Brandon, ECS Trans. 57 (2013) 3111.

[73] W.C. Chueh, Y. Hao, W. Jung, H.M. Sossina, Nat. Mater. 11 (2012) 155.

[74] H. Kim, S. Park, J.M. Vohs, R.J. Gorte, J. Electrochem. Soc. 148 (2001) A693.

[75] D.J.L. Brett, A. Atkinson, D. Cumming, E. Ramírez-Cabrera, R. Rudkin, N.P. Brandon, Chem. Eng. Sci. 60 (2005) 5649.

[76] S. Gewies, W.G. Bessler, J. Electrochem. Soc. 155 (2008) B937. 
[77] Z. Xie, C. Xia, M. Zhang, W. Zhu, H. Wang, J. Power Sources 161 (2006) 1056.

[78] M. Voigts, A. Kru, H. Schichlein, A.C. Mu, J. Appl. Electrochem. (2002) 875.

[79] J. Weese, Comput. Phys. Commun. 69 (1992) 99.

[80] S.M. Haile, Acta Mater. 51 (2003) 5981.

[81] S. Park, J. Vohs, R. Gorte, Nature 404 (2000) 265.

[82] A. Hornés, D. Gamarra, G. Munuera, A. Fuerte, R.X. Valenzuela, M.J. Escudero, L. Daza, J.C. Conesa, P. Bera, A. Martínez-Arias, J. Power Sources 192 (2009) 70.

[83] E.S. Putna, J. Stubenrauch, J.M. Vohs, R.J. Gorte, Langmuir 11 (1995) 4832.

[84] N. Guo, M.C. Leu, J. Fuel Cell Sci. Technol. 11 (2013) 011003.

[85] S. Chen, J. Murphy, J. Herlehy, D.L. Bourell, K.L. Wood, Rapid Prototyp. J. 12 (2006) 275.

[86] T. Czelusniak, F.L. Amorim, A. Lohrengel, C.F. Higa, Int. J. Adv. Manuf. Technol. 72 (2014) 905. 


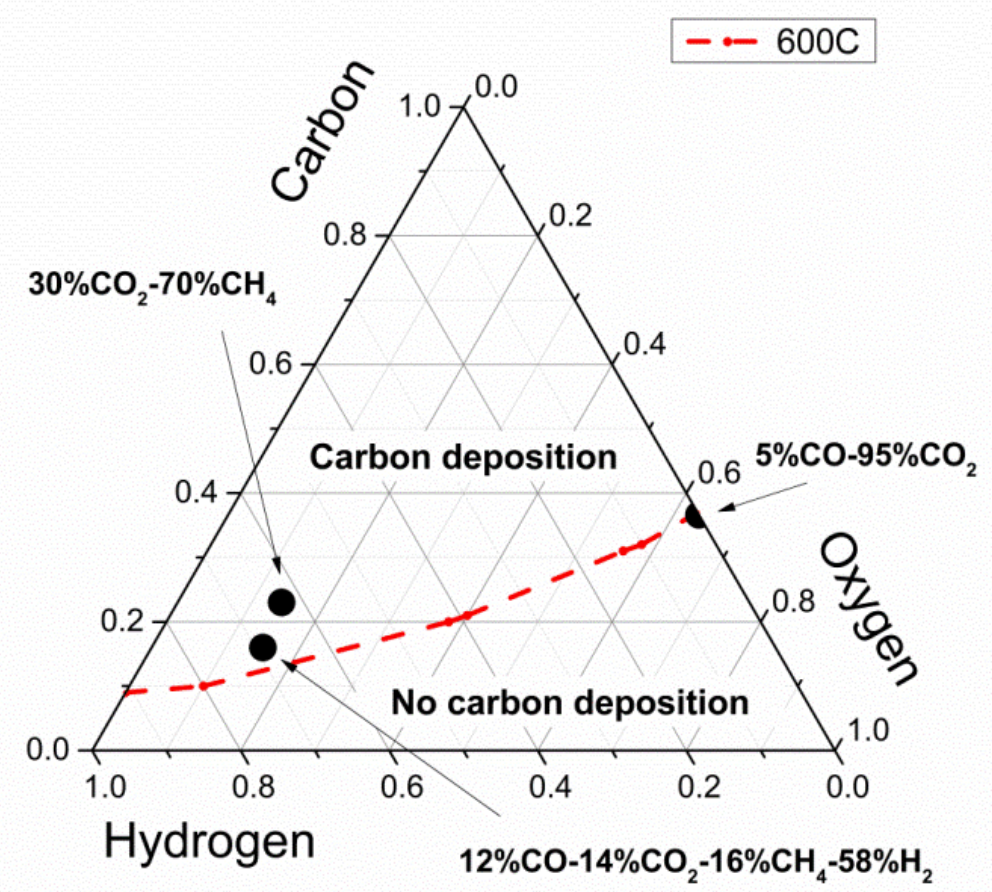

Fig. 1 Carbon deposition limits at $600^{\circ} \mathrm{C}$ in C-H-O ternary diagram.

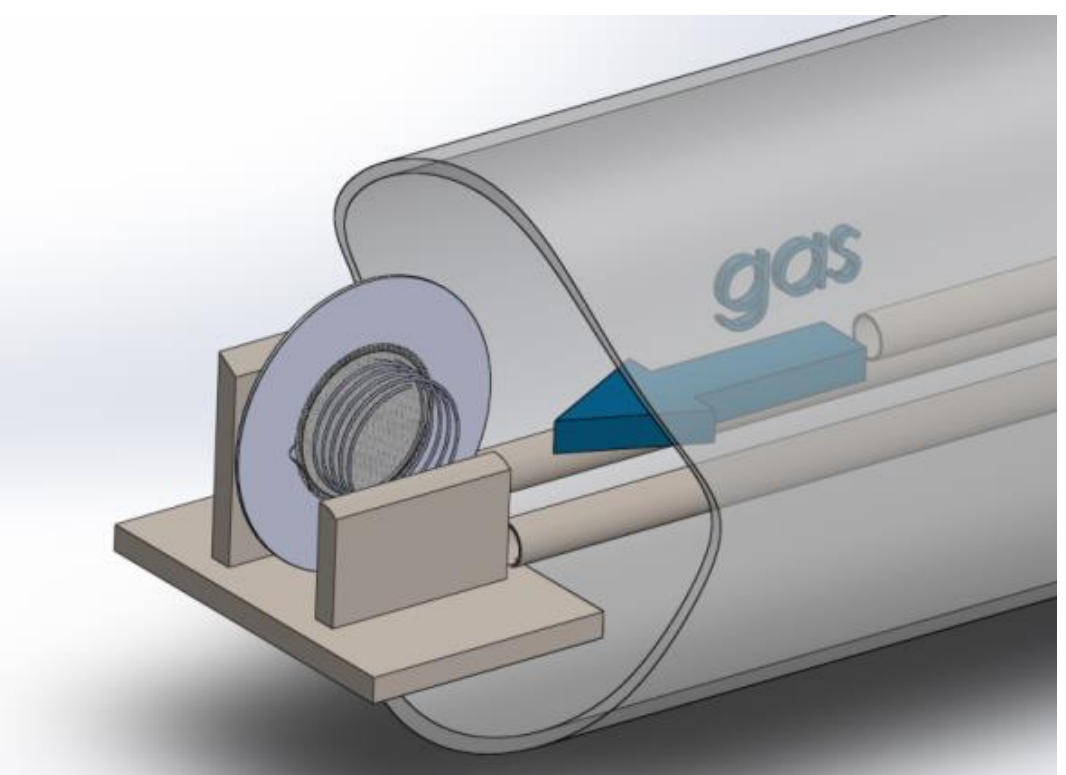

Fig. 1 Schematic illustration of the experimental configuration showing the current collection and gas distribution in the rig for symmetrical cell measurements. 

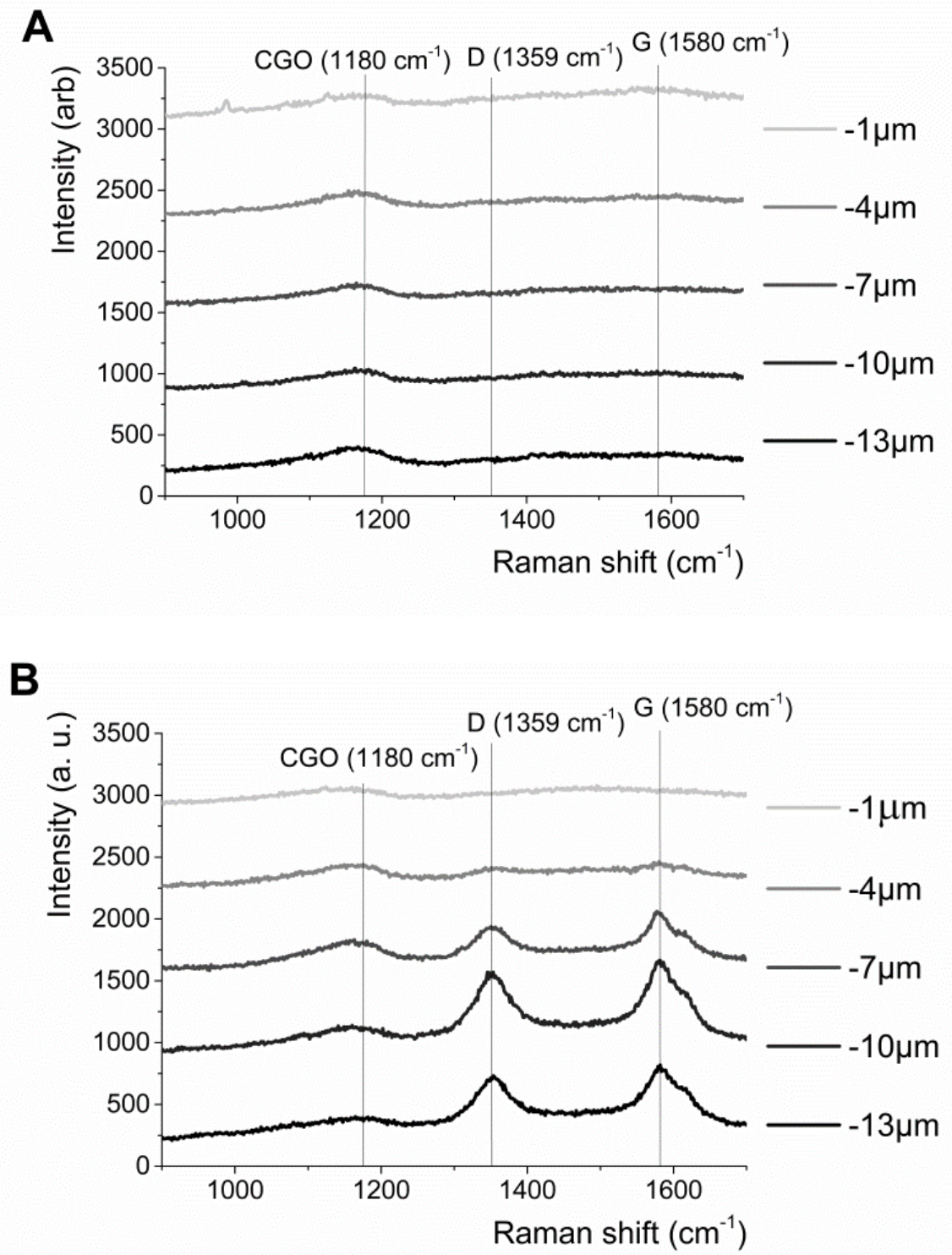

Fig. 2 Averaged Raman spectra collected ex-situ from the cross-section of a Ni impregnated CGO electrode along a single line at different distances from the surface ( $-1 \mu \mathrm{m}$ being adjacent to the surface) after 5 hours exposure to $95 \% \mathrm{CO} 2-5 \% \mathrm{CO}$ at (a) OCP and (b) -100mA. 
A
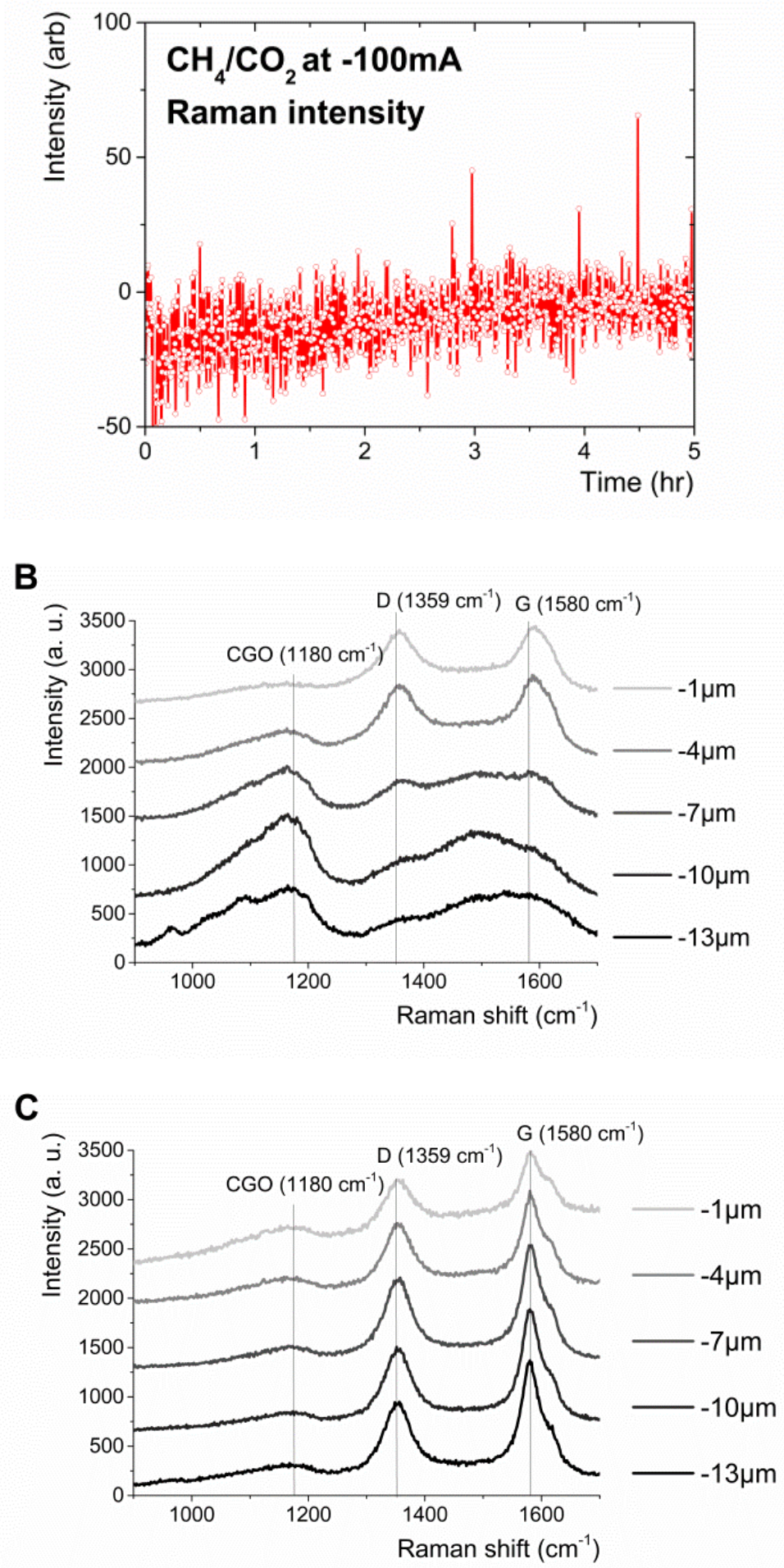

Fig. 3 (a) Integrated G peak area obtained from spectra collected in-situ from the surface of Ni/CGO electrode as a function of time during the electrode exposure to $70 \% \mathrm{CH} 4-30 \% \mathrm{CO} 2$ with $-100 \mathrm{~mA}$ bias. Raman spectra collected ex-situ from the cross-section of Ni impregnated CGO electrodes along a single line at different distances from the surface ( $-1 \mu \mathrm{m}$ being adjacent to the surface) after 5 hours exposure to $70 \%$ CH4 $30 \% \mathrm{CO} 2$ at (b) OCP and (c) $-100 \mathrm{~mA}$. 

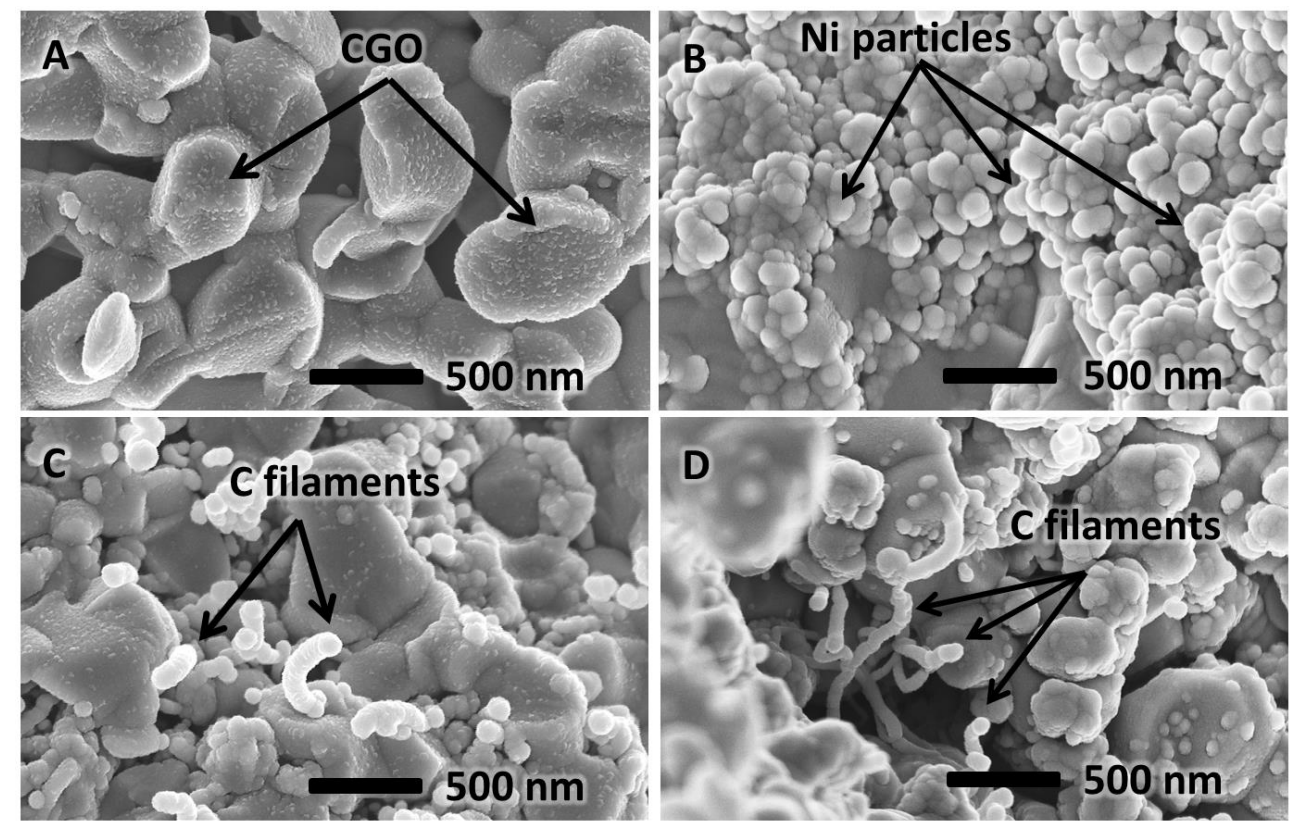

Fig. 4 SEM micrograph of (a) CGO scaffold before Ni infiltration; (b) x10 Ni-infiltrated CGO scaffold and x10 Ni-infiltrated CGO scaffold after 5 hour exposure to (c) $95 \% \mathrm{CO}_{2}-5 \% \mathrm{CO}$ and (d) $30 \% \mathrm{CO}_{2}-70 \% \mathrm{CH}_{4}$ with $-100 \mathrm{~mA}$ bias.
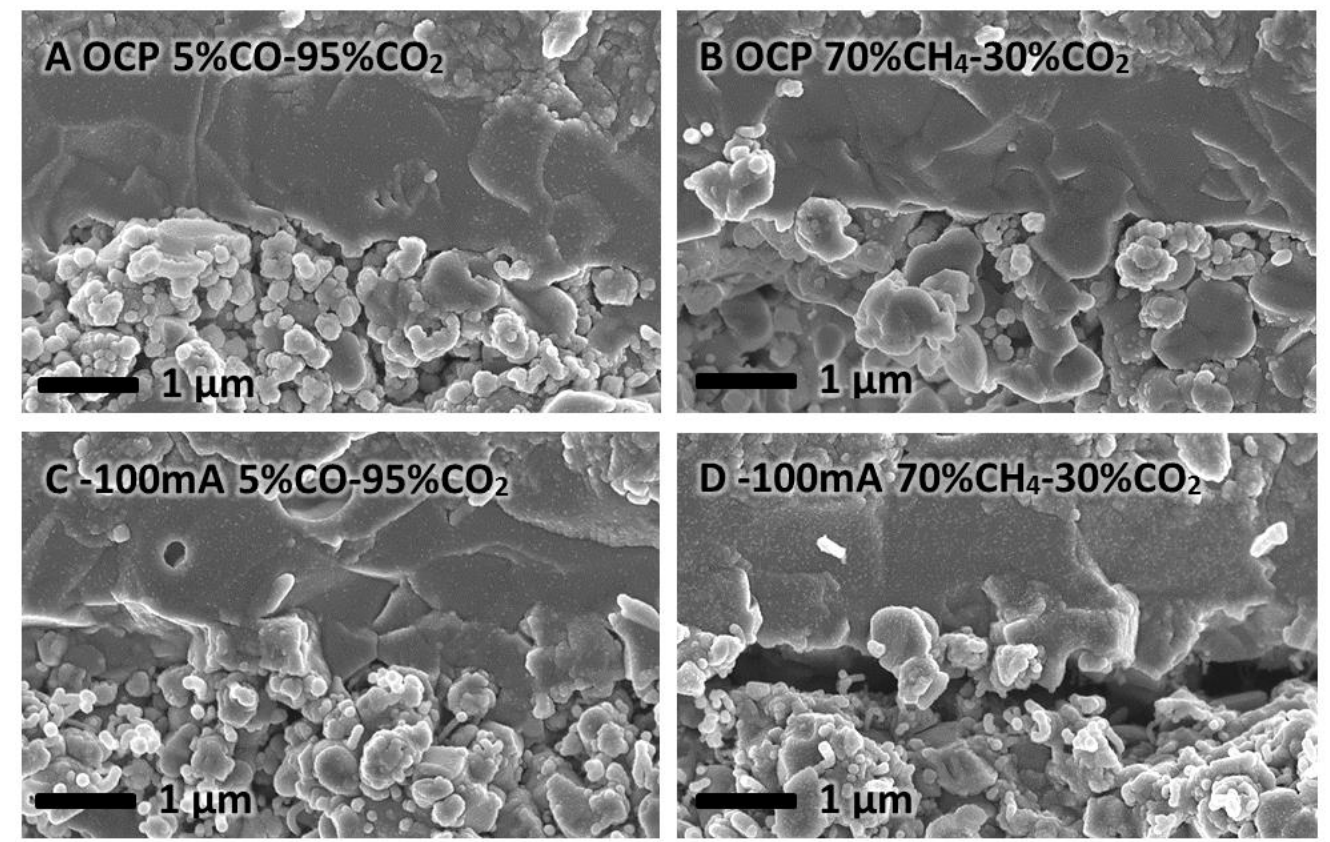

Fig. 5 SEM micrographs of the electrode/electrolyte interface after 5 hour exposure to the corresponding gas mixtures without (a, b) or with (c, d) bias of $-100 \mathrm{~mA}$. 
A

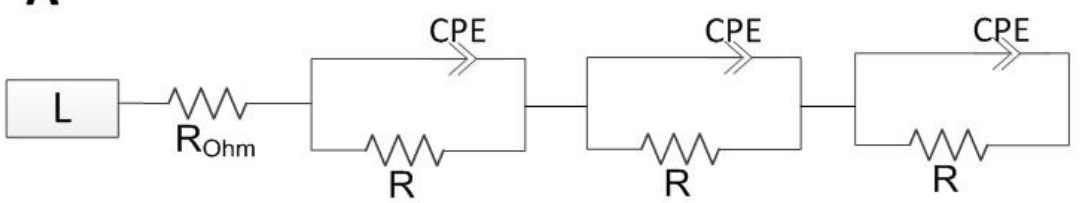

B

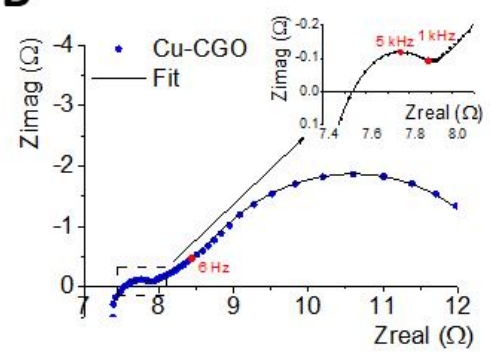

Cu-CGO

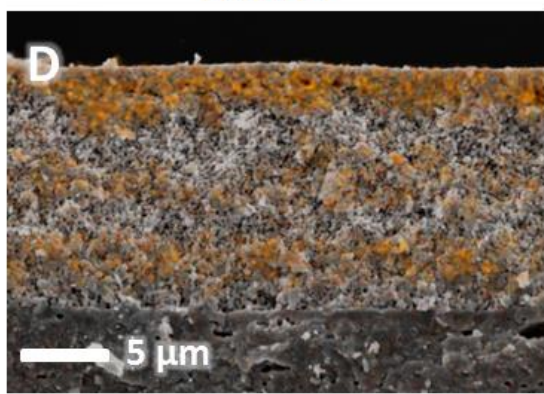

C

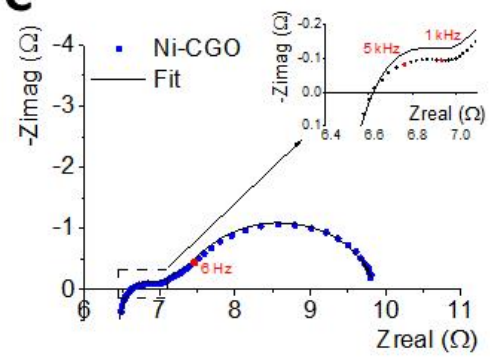

$\mathrm{Ni}-\mathrm{CGO}$

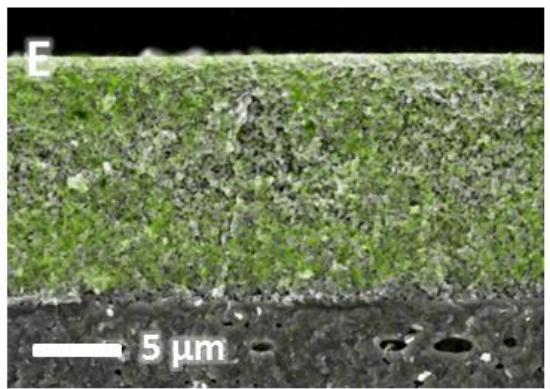

Fig. 6 EIS response of symmetrical cells at $600{ }^{\circ} \mathrm{C}$ in $50 \% \mathrm{H}_{2}$ and $50 \% \mathrm{~N}_{2}$, humidified at room temperature and (a) the equivalent circuit.

Symmetrical (b) Cu-CGO cell, (c) Ni-CGO cell. CS SEM-EDS micrographs of (d) Cu-CGO anode and (e) Ni-CGO anode. EDS analysis: orange $\mathrm{Cu}$, green $-\mathrm{Ni}$.

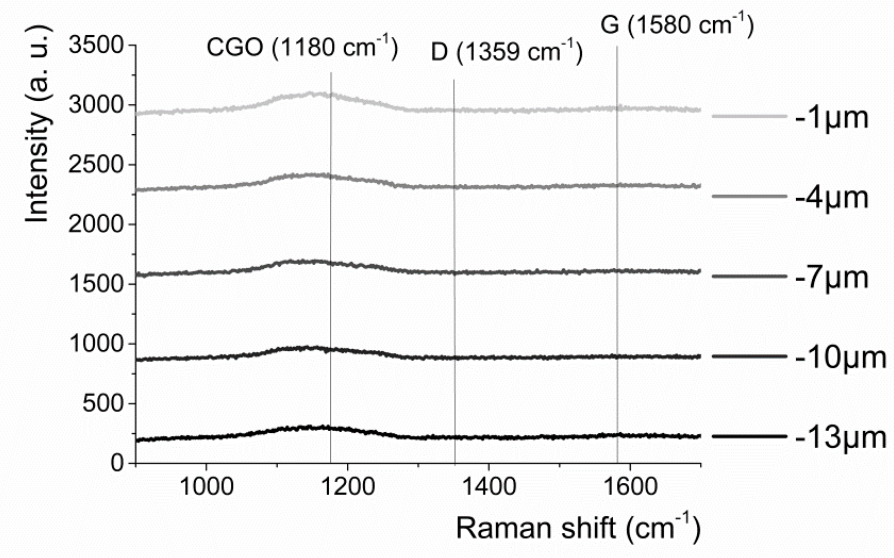

Fig. 7 Raman spectra collected $e x$-situ from the cross-section of $\mathrm{Cu}$ impregnated CGO electrodes along a single line at different distances from the surface ( $-1 \mu \mathrm{m}$ being adjacent to the surface) after 5 hours exposure to $70 \% \mathrm{CH}_{4}-30 \% \mathrm{CO}_{2}$ at $-100 \mathrm{~mA}$. 